\title{
ИЗУЧЕНИЕ ГРАДИЕНТА БИОЭЛЕКТРИЧЕСКОГО ПОТЕНЦИАЛА В КОРНЕОБИТАЕМОЙ СРЕДЕ
}

\author{
Кулешова Т.Э. ${ }^{1,2}$, Блохин Ю.И. ${ }^{2}$, Галль Н.Р. ${ }^{1}$, Панова Г.Г. ${ }^{2}$ \\ ${ }^{1}$ ФГБУН Физико-технический институт им. А.Ф. Иоффе Российской академии наук, \\ Санкт-Петербург, Россия, e-mail: piter.ru@bk.ru \\ ${ }^{2}$ ФББНУ Агрофизический научно-исследовательский институт, Санкт-Петербург, \\ Россия, e-mail: gaiane@inbox.ru
}

\begin{abstract}
The work is devoted to the study of the bioelectric potential gradient in the root zone using a noninvasive method. It is shown that the dynamics of biocurrents generated in the rhizosphere is associated with the development of the root system. The potential difference at the level of $250 \mathrm{mV}$ is also present in the soil without a plant, it decreases with time and the depth of the soil layer. The increase of the bioelectropotential by $150 \mathrm{mV}$ and more is observed in the presence of the root system, apparently, when it grows to the electrode.
\end{abstract}

Key words: bioelectric potential, root zone, non-invasive method, phytomonitoring, barley, electrogenesis

\section{Введение}

При развитии растений в корнеобитаемой среде возникает градиент биоэлектрического потенциала (БЭП), связанный как с внутренними процессами в растениях - регуляцией процессов жизнедеятельности клеток и растения в целом, электротонической передачей раздражений, морфогенетическими процессами, различиями в функционировании тканей и органов растений и т.д., так и с внешними - передвижением питательных веществ, водным режимом, окислительновосстановительными реакциями в почве [1-3]. По связи БЭП с факторами внешней среды можно косвенно судить о причинах электрогенеза [4]. Разность метаболических потенциалов является следствием различия интенсивности биохимических процессов в разных частях растения [5]. Изменение биопотенциалов в системе корнеобитаемая среда-растение служит чувствительным показателем состояния растительного организма и его реакции на влияние внешних условий и может быть использовано как перспективная система фитомониторинга.

Для эффективного исследования электрических явлений в живом организме и, в частности, транскорневых биоэлектрических потенциалов, способ отведения должен удовлетворять следующим условиям [6]: 1) обеспечивать надежный электрический контакт электрода с почвой, 2) учитывать влияние электрокинетических явлений в почве, исключать возможность возникновения диффузионного и поляризационного потенциалов в месте контакта почвы с электродом, 3) исключать возможность повреждения корней, 4) обеспечивать получение информации о жизнеспособности корней в различных точках вокруг их главной оси.

Цель настоящей работы заключалась в экспериментальном изучении градиента биоэлектрического потенциала в прикорневой зоне и его изменения в процессе развития растений.

\section{Материалы и методы}

Нами была разработана схема проведения эксперимента методом, не повреждающим растение, что позволяет изучать электрофизиологический сигнал растительного организма непосредственно в условиях нормальной жизнедеятельности. Мы использовали метод поверхностных неинвазивных измерений биоэлектрических потенциалов [7].

В качестве объекта для исследования был выбран яровой ячмень сорта Ленинградский. Испытания проводили на базе биополигона Агрофизического института в контролируемых условиях интенсивной светокультуры. В емкости для выращивания высотой 400 мм, на расстоянии 50 мм друг от друга были установлены сетки размером 190х190 мм² из нержавеющей

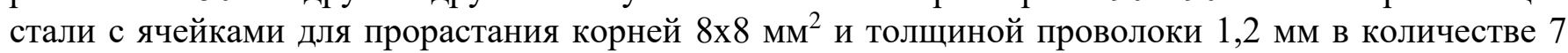
штук, пронумерованные начиная с 1-го верхнего электрода по порядку (рис. 1). За электрическую 
«землю» бы принят 7-ой электрод близлежащий к дну сосуда, измерения разности потенциалов велись относительно него, то есть между 1 и 7 электродами (U71), 2 и 7 электродами (U72) и т.д. Изначально остальные электроды были электроположительны по отношению к 7-му электроду.

Были взяты два идентичных сосуда, один из которых служил контролем для измерения разности потенциалов в почве без растения (№1), в другой были посажены пророщенный семена ячменя (№2). Емкости заполняли влажной почвой плотностью 1,2 и $\mathrm{pH} 5,9$, обогащенной питательными веществами и содержащей $4,16 \%$ органического вещества, $<2,8$ мг/кг азота нитратного, 26,1 мг/кг азота аммонийного, 397 мг/кг фосфора подвижного, 167 мг/кг калия подвижного. На 1 электроде находился слой почвы 30 мм, в который в сосуде №2 высаживали пророщенные семена ячменя в количестве 26 штук. Сетки выводились наружу через боковую поверхность емкости для выращивания и подключались к измерительному прибору.

Ранее было получено, что влажность почвы влияет на величину биопотенциалов, генерируемых в прикорневой зоне, а именно - полив растения и распространение воды от корневой шейки ко дну емкости для выращивания побуждает скачок БЭП на уровне 20-150 мВ в зависимости от длительности выдержки растения без полива $[7,8]$. В связи с этим сосуды с почвой с влажностью на уровне $\sim 60-70 \%$ от полной влагоемкости и электродами взвешивались, и их масса поддерживалась постоянной в течение всего эксперимента за счет осуществления ежедневного полива сверху.

Для автоматизации эксперимента и on-line мониторинга биоэлектрических потенциалов растений использовали платформу для разработки электронных устройств Arduino Mega 2560, базирующаяся на микроконтроллере ATmega2560 и связанная с ПК через USB-кабель. Входное сопротивление устройства составляет 100 кОм.

Программный код (скетч), написанный на языке Arduino, позволяет регистрировать и записывать разность потенциалов на электродных сетках раз в секунду или реже, в зависимости от задачи. В программе позволяющей применять микроконтроллер в качестве вольтметра, записывающего данные в режиме реального времени, использовали: библиотеку для работы с шиной SPI для адаптера карт Micro SD и библиотеку для работы с адаптером карт Micro SD; функцию pin Mode, которая устанавливает режим работы заданного входа; функцию analog Read для чтения данных с указанного аналогового входа;

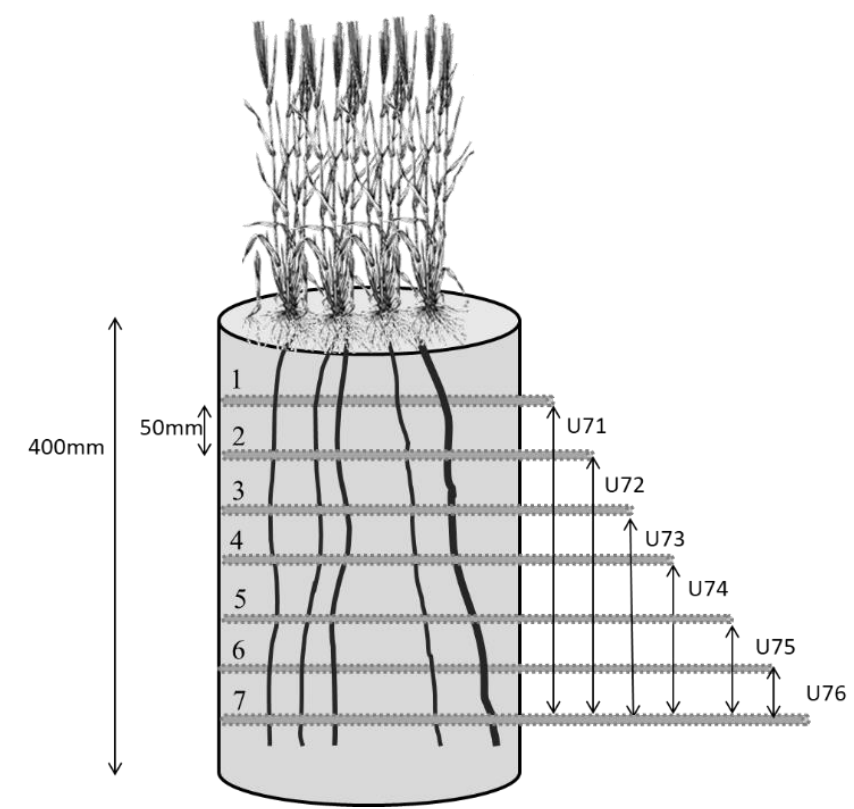

Рисунок 1. Схема расположения электродов 1-7 по вертикали почвы для измерения разности потенциалов.

функцию data File. print для сохранения информации на SD-карту, функцию delay для остановки выполнения программы на заданное в параметре количество миллисекунд. Регистрация БЭП осуществлялась каждые 15 минут в многосуточном режиме. 


\section{Результаты и обсуждение}

В результате проведенного эксперимента определено изменение разности потенциалов в зависимости от глубины почвы (рис. 2A). В почве без растения напряжение спадает с уменьшением расстояния между электродами. Напряженность в первые 30 дней эксперимента составляет $\sim 0,8$ В/м и уменьшается ко дну сосуда. Из этого следует, что поток воды, вносимый в систему ежедневно, запускает на электродах ряд физико-химических реакций (диффузию, окислительновосстановительные процессы), интенсивность которых спадает по мере движения жидкости в глубину почвы. Также заметно снижение разности потенциалов со временем, что, по-видимому, связано с замедлением процессов в почве, запущенных при внесении раствора макро- и микроэлементов в начале эксперимента.

В тоже время распространение корней по системе электродов изменяет величину БЭП в связи с диффузией питательных веществ из почвы и выделением ризодепозитов. В первые дни значения практически не отличаются. Развивающиеся корни быстро достигают 2-ого электрода и на начальных периодах вегетации на нем стабильно фиксируется разность потенциала относительно электрода 7. На 14 день наблюдалось начало фазы кущения, однако значительные изменения БЭП при этом не зафиксированы. На 25 день заметно увеличение биоэлектрических потенциалов между электродами 7 и 3. Это можно объяснить прорастанием и контактом корней с электродной сеткой 3 , а со временем и сеткой 4.

Изначально ток шел от отрицательного электрода 7 к положительным 1-6. Это может означать движение питательных веществ по градиенту почвы к надземной части растения. Однако примерно на 45 день полярность изменилась, в связи с этим дальнейшие измерения проводили относительно электрода 1. Среднее значений БЭП на 50-60 дни эксперимента составило U12= $15 \mathrm{MB}, \mathrm{U} 13=-237 \mathrm{mB}, \mathrm{U} 14=-177 \mathrm{mB}, \mathrm{U} 15=-216 \mathrm{mB}, \mathrm{U} 16=-225 \mathrm{MB}, \mathrm{U} 17=-240 \mathrm{MB}$. Интересно отметить, что разность потенциалов между почти всеми сетками относительно новой «земли» электрода 1 практически одинакова, из чего следует, что напряженность между соседними электродами уменьшается ко дну сосуда от 2,3 В/м до 0,8 B/м.

Средние значения тока утечки лежали в районе 50 нА, максимальная величина тока 82 нА зафиксирована на 50-60 дни эксперимента.
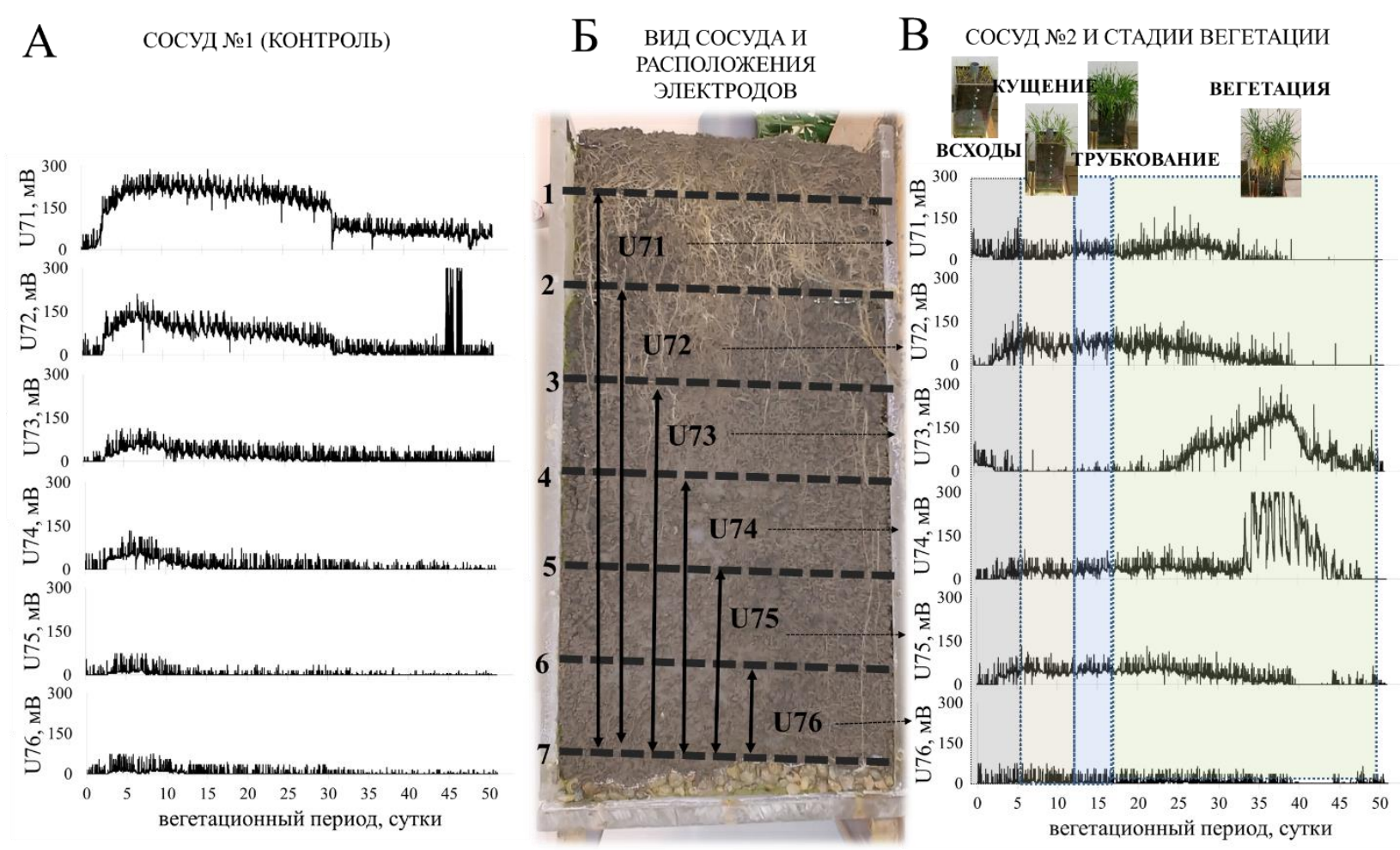

Рисунок 2. Динамика разности потенциалов по градиенту глубины: : А в почве, Б, $B$ - в почве при развитии корневой системы ячменя Ленинградского. 


\section{Выводы}

Изменение разности потенциалов по градиенту почвы наблюдается и при развитии корневой системы и просто в почвенной структуре. Это говорит о наличии процессов ионного транспорта, протекающих в грунте даже без растительных организмов, только за счет диффузии водного потока. Растение, очевидно, запускает дополнительные реакции, поглощая и выделяя различные органические и минеральные соединения, и увеличивает интенсивность почвенных процессов, реагируя с микроорганизмами ризопланы, ризосферы и, видимо, влияя на скорость диссоциации солей.

Дальнейшие исследования биоэлектрогенеза в прикорневой зоне позволят оценить роль БЭП как параметра мониторинга состояния растительных организмов. Генерируемые биотоки могут быть также основой для создания технологии накопления и производства электроэнергии с помощью комбинации высших растений и микробных топливных элементов - растительномикробных топливных элементов (РМТЭ).

\section{Литература}

1. КУТИМСКАЯ, М.А., БУЗУНОВА, М.Ю., УБРЯТОВА, Л.В. Биоэлектрогенез и информационный обмен у высших растений, включая зерновые культуры // Вестник ИрГСХА. 2014. №. 60. С. 105-110.

2. BRENNER, E.D., STAHLBERG, R., MANCUSO, S., VIVANCO, J., BALUŠKA, F., VAN VOLKENBURGH, E. Plant neurobiology: an integrated view of plant signaling // Trends in plant science. 2006. V. 11. №. 8. P. 413-419.

3. ПОЗДНЯКОВ, А.И. Биоэлектрические потенциалы в системе почва растение // Почвоведение. 2013. №. 7. С. 813-821.

4. КОЛОВСКИЙ, Р.А. Биоэлектрические потенциалы древесных растений. Новосибирск: Наука, 1980. 176 с.

5. ОПРИТОВ, В.А., ПЯТЫГИН, С.С. Биоэлектрогенез у высших растений М.: Наука, 1991. 216 с.

6. БИЧИАШВИЛИ, Т.Г., ЦАНАВА, В.П., СОЛОВЬЕВ, Е.В., МАРИЧЕВ, Г.А. Комплекс электрофизиологических и электрохимических методов диагностики физиологического состояния субстропических культур // Биофизика растений и фитомониторинг: Сборник научных трудов. Л.:АФИ, 1990. С. 128-139.

7. КУЛЕШОВА, Т.Э., БУШЛЯКОВА, А.В., ГАЛЛЬ, Н.Р. Неинвазивное измерение биоэлектрических потенциалов растений // Письма в ЖТФ. 2019. Т. 45. №. 5. С. 6-8.

8. КУЛЕШОВА, Т.Э., ШЕИНА, И.Ю., ЧЕРНОУСОВ, И.Н., УДАЛОВА, О.Р., БЛОХИН, Ю.И., АЛЕКСАНДРОВ, А.В., ЖЕСТКОВ, А.С., ПАНОВА, Г.Г., ГАЛЛЬ, Н.Р. КомПЛекс неинвазивнЫх измерений оптических свойства листьев и биопотенциалов растений для фитомониторинга // Материалы II Международной научной конференции «Тенденции развития агрофизики: от актуальных проблем земеледелия и растениеводства к технологиям будущего», посвященной памяти академика Е.И. Ермакова. СПб.: ФГБНУ АФИ. 2019. С. 212-219. 